\title{
Determinação de Ácidos Graxos em Genótipos de Cafés (Coffea canephora) por Ressonância Magnética Nuclear
}

\author{
Alves, A. L. ${ }^{1 *}$; Izoton, T. M. ${ }^{2}$; Velloso, M. R. ${ }^{1}$; Partelli, F. L. ${ }^{3}$;Pessoa M. S. ${ }^{1}$; Moscon, P. ${ }^{1}$ \\ 1 Departamento de Ciências Naturais, Universidade Federal do Espírito Santo, São Mateus, ES, Brasil. \\ 2 Graduanda em Engenharia Química, Universidade Federal do Espírito Santo, São Mateus, ES, Brasil. \\ 3 Departamento de Ciências Agrárias, Universidade Federal do Espírito Santo, São Mateus, ES, Brasil. \\ *e-mail: andluial@yahoo.com.br
}

\begin{abstract}
Resumo
Neste trabalho, foi determinada a fração lipídica de ácidos graxos de seis genótipos de cafés da espécie Coffea Canephora (robusta), conhecidas por se destacarem com excelentes produtividades em regiões de clima tropical. Os grãos de cafés tiveram as frações de baixa polaridade extraídas com hexano e a técnica de Ressonância Magnética Nuclear de ${ }^{1} \mathrm{H}\left(\mathrm{RMN}\right.$ de $\left.{ }^{1} \mathrm{H}\right)$ foi usada na identificação e quantificação dos ácidos graxos. Os resultados obtidos apresentaram concordância com os obtidos por técnicas de cromatografia e, portanto, parâmetros de qualidade puderam ser atribuídos aos grãos. Três genótipos se destacaram por apresentarem maiores frações de ácidos graxos insaturados, podendo o consumo dos grãos verdes, serem indicados como suplemento alimentar, devido aos baixos níveis de gorduras e colesterol. Entretanto, maiores cuidados devem ser tomados com relação à estocagem destes grãos, devido a maior oxidação lipídica que pode ocorrer nos ácidos graxos insaturados.
\end{abstract}

\begin{abstract}
In this work, the fatty acid lipid fraction of six coffee genotypes of the Coffea Canephora (robusta) species was determined. These species are known for their high yields in tropical climate crops. The low polarity fractions were extracted from coffee beans with hexane. The quantification of fatty acids was determined by the ${ }^{1} \mathrm{H}$ NMR technique. The results obtained by NMR showed agreement with those obtained by the chromatographic technique and, therefore, quality parameters could be attributed to the beans. Three genotypes were distinguished by the fact that they presented higher fractions of unsaturated fatty acids, providing quality parameters to the bean, since their consumption would be associated with low levels of fats and cholesterol. However, greater care should be taken in relation to the storage of these beans, due to the greater lipid oxidation that can occur in unsaturated fatty acids.
\end{abstract}

Keywords: Fatty acids, Coffee genotypes, RMN, Genetic selection.

\section{Introdução}

O café é um produto que apresenta grande destaque na indústria de alimentos e de cosméticos [1 - 3]. Adicionalmente, as propriedades de aroma e sabor de sua bebida fazem com que este seja um dos produtos agrícolas mais produzidos em todo o mundo [4 - 6]. O Brasil se destaca como o maior produtor mundial, e estima-se que na safra de 2018 , sejam produzidas entre 54,44 milhões e 58,51 milhões de sacas de $60 \mathrm{~kg}[6,7]$. Neste cenário, o estado do Espírito Santo se destaca como o maior produtor nacional da espécie robusta, sendo responsável por $75 \%$ - $78 \%$ da produção nacional [8]. Devido a esta grande produtividade, os grãos de cafés podem ficar armazenados por um longo período e, associado à forma inadequada de armazenamento, ocorrem degradações e oxidações de seus componentes químicos, diminuindo seu valor de mercado [9]. Desta forma, busca-se obter variedades genéticas que apresentem frações de componentes químicos que definem superioridade dos grãos em produtividade, resistência a pragas e a degradações durante o armazenamento [10,11]. Dentre os vários componentes químicos encontrados nos grãos, a fração lipídica do café verde é rica em matéria insaponificável e, quando presentes na formulação de cremes cosméticos, podem constituir o princípio ativo 
de muitas propriedades desejáveis como retenção de umidade, penetração na pele e aderência [3, 12]. Além disto, a fração correspondente aos ácidos graxos insaturados pode servir como parâmetro de avaliação de oxidação durante o armazenamento [13, 14]. Neste trabalho, foi quantificada a fração lipídica correspondente aos ácidos graxos de seis variedades genéticas de grãos verdes de cafés da espécie robusta, cultivadas no Espírito Santo - Brasil. Foi utilizada a técnica de extração apolar com hexano e subsequente análise com a técnica de $\mathrm{RMN}$ de ${ }^{1} \mathrm{H}$ dos extratos obtidos. Foi possível distinguir quais dos genótipos apresentaram maiores frações de ácidos graxos dos tipos saturados e insaturados sendo possível atribuir parâmetro de qualidade aos grãos.

\section{Materiais e Métodos}

Os genótipos de cafés denominados de Baiano, Bamburral, Beira Rio, Clementino, Pirata e Coringa, são provenientes de cruzamentos naturais e se destacam por apresentarem excelentes produtividades em regiões de clima tropical. No Espírito Santo, nas safras de 2014 e 2015, estas variedades se destacaram dentre outras, com produtividade superior a 70 sacas/ha [15]. As lavouras foram implantadas no estado em maio de 2012, no município de Vila Valério ES. Foi adotado espaçamento de 2,7 metros por linhas e 1,2 m entre plantas, estabelecendo uma densidade de 3086 plantas por hectare. Nesta localidade o clima é tropical, com temperatura média de $23^{\circ} \mathrm{C}$, caracterizado pelo verão quente e úmido, e inverno seco, de acordo com a classificação proposta por Köppen, apresentando precipitação média anual de $1200 \mathrm{~mm}$ [16]. Após colheita, os frutos foram despolpados e os grãos foram secos em forno com ventilação forçada de ar durante sete dias a uma temperatura de $40{ }^{\circ} \mathrm{C}$. Os mesmos foram armazenados em refrigeração à temperatura de $10{ }^{\circ} \mathrm{C}$ durante um período de 2 a 5 meses, para posterior análise de $\mathrm{RMN}$ de ${ }^{1} \mathrm{H}$.

Para a extração da fração apolar, $10 \mathrm{~g}$ de cada amostra foram colocadas em um cartucho de celulose vedado com algodão. O cartucho foi inserido no extrator de soxhlet que, posteriormente, foi acoplado em um balão de fundo redondo de $250 \mathrm{~mL}$, contendo $150 \mathrm{~mL}$ de hexano com $99,9 \%$ de pureza. O extrator foi conectado ao sistema de circulação de água e aquecido por uma manta. Após a ebulição, o sistema ficou em refluxo por um período de $4 \mathrm{~h}$ e, posteriormente, resfriado até a temperatura ambiente. O solvente foi evaporado em um evaporador rotativo. As extrações foram realizadas em triplicata.

Os espectros de RMN de ${ }^{1} \mathrm{H}$ foram obtidos de forma quantitativa, a temperatura de $20{ }^{\circ} \mathrm{C}$ em um equipamento Varian (USA), modelo VNMRS com campo de 11,75 Tesla (500 MHz na frequência do ${ }^{1} \mathrm{H}$ ). Como solvente utilizou-se clorofórmio deuterado $\left(\mathrm{CDCl}_{3}\right)$ e como referência interna ao Tetrametilsilano (TMS). A concentração de todas as amostras foi de aproximadamente $1: 3 \quad(\mathrm{v} / \mathrm{v})$. Os espectros obtidos consistem da intensidade do sinal em função do deslocamento químico com referência ao TMS, em partes por milhão (ppm). Para cada extração, foi realizado um espectro de $\mathrm{RMN}$.

\section{Resultados e Discussões}

As extrações das frações apolares do café permitem separar os lipídeos, de compostos dos tipos polares como a cafeína, ácidos clorogênicos, trigonelina e outros, tornando mais simples a interpretação dos espectros de RMN de ${ }^{1} \mathrm{H}$ das amostras. Na Figura 1, está representado o espectro para da extração obtida do genótipo denominado Baiano.

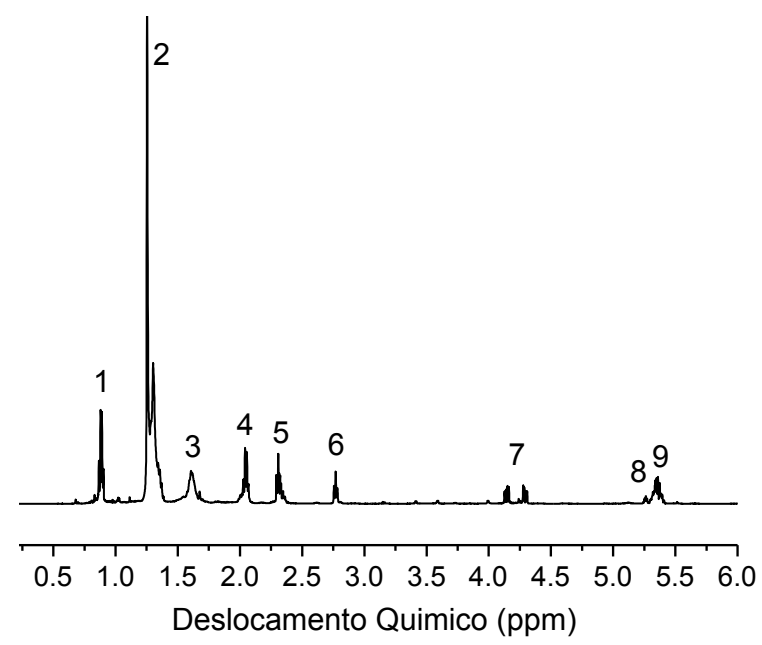

Figura 1 - Espectro de RMN de ${ }^{1} \mathrm{H}$ do extrato da fração apolar para o genótipo de café denominado Baiano.

As posições dos picos de ressonância de todos os genótipos foram análogas aos deste espectro. Uma análise superficial do padrão de deslocamento químico, multiplicidade e intensidade dos sinais indicam que $o$ 
espectro é típico de um triglicerídeo $[17,18]$. Os triglicerídeos, que aparecem na fração lipídica de grãos de cafés, são triésteres, formados pela união de três moléculas de ácidos graxos com uma molécula de glicerol. Estes podem ser óleos, derivados de Ácidos Graxos Insaturados (AGI) e, gorduras, derivados de Ácidos Graxos Saturados (AGS) [19].

Os sinais de um espectro de $\mathrm{RMN}$ de ${ }^{1} \mathrm{H}$ de lipídeos são assinalados em grupos de hidrogênios não equivalentes que são comuns a todas as cadeias de ácidos graxos [17, 18]. Assim, a identificação dos picos do espectro obtido, foi realizada como se segue: 0 sinal 1, em 0,89 ppm refere-se aos hidrogênios metílicos terminais, presente em cadeias graxas. O sinal 2, em 1,24 ppm é referente aos hidrogênios metilênicos presentes nas estruturas de todas as cadeias alquila. $O$ sinal 3, em 1,60 ppm, é referente aos hidrogênios metilênicos $\beta$ de grupo carbonila $\left(\beta-\mathrm{CH}_{2}\right)$ e, o sinal 5, em 2,30 ppm é referente aos hidrogênios metilênicos $\alpha$ de grupo carbonila $\left(\alpha-\mathrm{CH}_{2}\right)$. O sinal 4 em 2,05 ppm é referente aos hidrogênios alílicos das cadeias de ácidos graxos insaturados, enquanto os metilênicos bisalílicos das cadeias de ácidos graxos polinsaturadas, aparecem no sinal 6 , em 2,80 ppm. 0 sinal 7, referente aos duplos dupletes em 4,15 e 4,30 ppm, são devidos as ressonâncias dos hidrogênios glicerídicos das posições 1 e 3. O sinal 8, em 5,26 ppm, se refere ao hidrogênio glicerídico da posição 2 e, finalmente, o sinal 9 é referente a um multiplete em torno de 5,36 ppm, devido a ressonância dos hidrogênios olefínicos $(-\mathrm{CH}=\mathrm{CH}-)$ presentes em todas as cadeias de ácidos graxos insaturados.

A boa resolução dos hidrogênios metílicos e metilênicos, na região de $0,80-3,00$ ppm do espectro, permite uma extração satisfatória de informações a cerca da composição e fração de ácidos graxos. Portanto, as frações percentuais destes ácidos foram calculadas pela combinação da intensidade dos vários sinais, seguindo os procedimentos propostos por SACCHI et al., 1996 e VIGLI et al., 2003 [18, 20]. Os resultados obtidos, nas extrações de cafés em estudo, estão apresentados na Tabela $1 \mathrm{com}$ seus respectivos desvios padrões amostrais. Foi possível verificar que as frações de AGI são predominantes sobre os AGS, estando de acordo com resultados obtidos para as espécies Robusta e Arábica [2, 17, 21]. Os genótipos Clementino, Coringa e Pirata, apresentaram maiores frações de AGI, com predominância do ácido Linoleico ( $\omega-6)$, em concordância com valores obtidos na literatura $(40-50 \%)[17,22]$. Entretanto, os genótipos: Baiano, Bamburral e Beira Rio apresentaram valores inferiores aos aceitáveis. Considerando que o ácido linoleico, sendo poli-insaturado, é facilmente oxidado pelo oxigênio, por meio de uma reação radicalar em cadeia [22, 23], a diferença observada indica a ocorrência de um processo de oxidação do ácido linoleico, conduzindo um decréscimo em sua fração.

De acordo com a Tabela 1, o ácido Linolênico ( $\omega-3)$ é minoritário, na faixa de $1.4-4 \%$, seguido do Oleico $(\omega-9)$, entre 15 - $20 \%$. Ambos os valores são ligeiramente maiores que os obtidos na literatura, por cromatografia gasosa, estando entre $0.6-1.6 \%$ para o ácido Linolênico e 7.3 - 11.9\%, para o Oleico [17, 22, 23]. Geralmente, diferenças de concentrações estão associadas ao fato de que a técnica de RMN, fornece valores fracionais, ao invés de quantitativos [17].

Tabela 1 - Valores fracionais de Ácidos Graxos Insaturados (AGI) dos tipos Linolênico, Linoleico e Oleico e Saturados (AGS) na composição lipídica dos genótipos de cafés.

\begin{tabular}{ccccc}
\hline \hline \multirow{2}{*}{ Genótipo } & \multicolumn{3}{c}{ AGI (\%) } & \\
& Linolênico & Linoleico & Oleico & AGS (\%) \\
\hline Baiano & $4 \pm 1$ & $31 \pm 4$ & $20 \pm 2$ & $45 \pm 3$ \\
\hline Bamburral & $1.4 \pm 0.3$ & $35.3 \pm 0.6$ & $21.1 \pm$ & $42.2 \pm 0.3$ \\
\hline Beira Rio & $1.9 \pm 0.3$ & $38 \pm 5$ & $18 \pm 4$ & $42 \pm 4$ \\
\hline Clementino & $3.2 \pm 0.1$ & $47 \pm 4$ & $21 \pm 3$ & $28 \pm 5$ \\
\hline Coringa & $3.1 \pm 0.4$ & $46 \pm 4$ & $19 \pm 2$ & $32 \pm 3$ \\
\hline Pirata & $3.1 \pm 0.2$ & $52 \pm 1$ & $15 \pm 3$ & $30 \pm 3$ \\
\hline \hline
\end{tabular}

Para uma análise mais detalhada das frações de AGI e AGS foi realizado um gráfico em forma de barras, apresentado na Figura 2. Uma análise da fração de AGI nos genótipos permite concluir que o genótipo Baiano apresentou maior fração do ácido Linolênico. Os genótipos Clementino, Coringa e Pirata, apresentaram valores intermediários deste ácido e são semelhantes em fração. Por outro lado, os genótipos Bamburral e Beira Rio apresentaram menor fração deste ácido. 


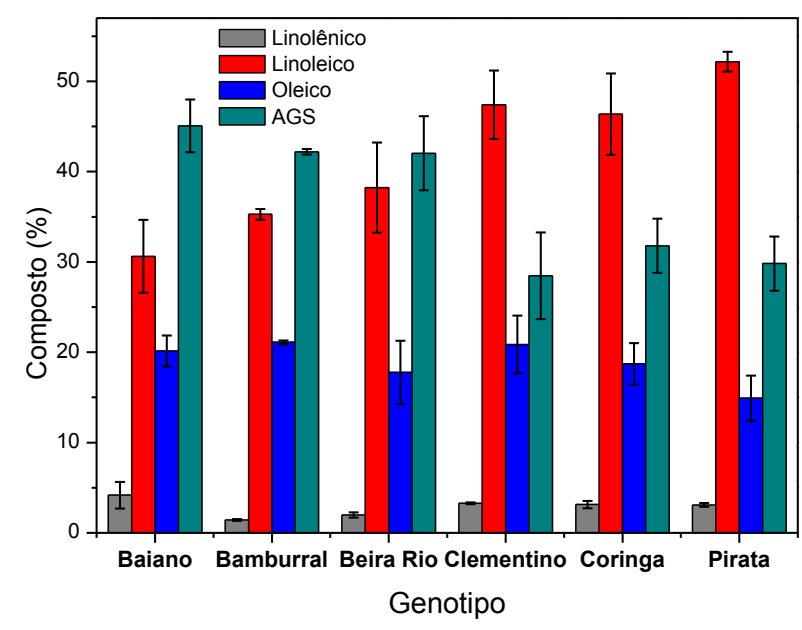

Figura 2 - Composição fracional de AGI e AGS nos genótipos de cafés. Os traços pretos, verticais indicam o desvio padrão da fração de cada composto.

Quanto ao ácido Linoleico, o genótipo Pirata apresentou maior fração, seguido dos genótipos Coringa e Clementino, que apresentaram frações semelhantes. Os genótipos Beira Rio e Bamburral possuem frações semelhantes, apresentando baixa fração deste ácido. O genótipo Baiano foi o que apresentou menor fração de ácido linoleico. Quanto ao ácido Oleico, o genótipo Pirata apresentou menor fração, sendo que os demais genótipos não se distinguiram em valor. Com relação aos AGS, os genótipos Baiano, Bamburral e Beira Rio, apresentaram valores semelhantes e são superiores aos dos genótipos Clementino, Coringa e Pirata, que são semelhantes.

Estudos demonstram que dietas com alimentos ricos em de AGI, trazem benefícios à saúde humana, pois são essenciais na diminuição da proporção de Lipoproteínas de Baixa Densidade (LDL) relativas à de Alta Densidade (HDL) [24]. Neste contexto, o ácido linolênico é capaz de ajudar no controle da lipidemia e conter reações inflamatórias, tornando-se coadjuvante no tratamento de doenças cardiovasculares [25, 26]. Por sua vez, o ácido linoleico atua na formação das membranas celulares, auxilia na síntese hormonal, no correto funcionamento do sistema imunológico e no funcionamento neuronal. A participação do ácido Oleico no metabolismo desempenha um papel essencial na síntese dos hormônios [25]. Um fator de grande importância de alimentos ricos nestes ácidos vem do fato de que organismos animais não conseguem sintetizá-los, tornando essenciais seus consumos. Por outro lado, o consumo de alimentos com elevados valores de AGS, contribui com a elevação do colesterol do tipo LDL aumentando o risco cardiovascular [26, 27]. Levando em consideração estas questões, os genótipos Clementino, Coringa e Pirata, podem desempenhar um importante papel na saúde humana, quando consumidos os grãos na forma verde (sem a torrefação), pois estes contêm maiores frações de AGI. Entretanto, deve-se ter mais prudência durante 0 armazenamento e estocagem destes genótipos, visto que a oxidação/ degradação em grãos ocorrem nos ácidos graxos insaturados, principalmente no linoleico, levando a formação de produtos como aldeídos, cetonas, alcoóis, ácidos e hidrocarbonetos. Estes produtos são responsáveis pelas características organolépticas e físico-químicas associadas com a rancificação dos grãos e perda de sabor da bebida após torrefação [22, 23, 25]. Como os genótipos Baiano, Bamburral e Beira Rio apresentarem baixas frações de AGI, estes seriam, a priori, mais resistentes a formas de oxidação lipídica.

É importante lembrar que o estudo realizado aqui, diz respeito apenas aos ácidos graxos e, estes por si só, não definem completamente a superioridade dos grãos. Esta depende de um estudo geral da composição química, da atividade antioxidante e de testes de bebida.

\section{Conclusões}

Através da utilização da técnica de $\mathrm{RMN}$ de ${ }^{1} \mathrm{H}$ foi possível determinar a fração de ácidos graxos em genótipos de cafés (Coffea Canephora), permitindo identificar e quantificar os tipos de AGI e AGS totais. Os genótipos Clementino, Coringa e Pirata se destacam por apresentarem maiores quantidades de AGI, tornando-se importantes como suplementos alimentares. Apesar dos genótipos Baiano, Bamburral e Beira Rio apresentaram baixas frações de AGI, estes podem apresentar destaque na resistência à oxidação lipídica decorrentes de processos de armazenagem. $O$ café Pirata se destacou em termos de fração AGI/AGS, podendo tornar-se promissor, como café verde rico em lipídios saudáveis. 


\section{Agradecimentos}

Agradecemos a FAPES por todo apoio financeiro concedido.

\section{Referências}

[1] BREZOVÁ, V.; SLEBOdOVÁ, A.; STASCO, A. Food Chem., v. 114, p. 859-868, 2009.

[2] SPEER, K.; KOLLING-SPEER. Braz. J. Plant. Physiol., v.18, p. 201-216, 2006.

[3] WAGEMAKER, T. A. L.; FERNANDES, A. S. et al. Biomed Biopharm. Res. J., v.9, p. 207-214, 2012.

[4] HAMER, H. J. Human Hypertens, v. 20, p. 909-912, 2006.

[5] DEBRY, G. Coffe and health. Paris: Jhon Libbey Eurotex: ISBN 2, 7420-0037-2, 1994.

[6] Cecafé - Conselho dos exportadores de café do Brasil, São Paulo. Disponível em <http://www.ceca fe.com .br/sobre-o-cafe/producao>. Acesso em: 29 Abr. 2018.

[7] Agência Brasil, São Paulo. Disponível em <http://agenciabrasil.ebc.com.br/economia/noticia/2018 -01/conab-estima-producao-de-cafe-em-2018-entre-21e-30-superior-ao-ano-passado>. Acesso em: 30 Abr. 2018.

[8] Incaper - Instituto Capixaba de Pesquisa, Assistência Técnica e Extensão Rural. Disponível em $<$ https://incaper.es.gov.br/cafeicultura-conilon>. Acesso em: 30 Abr. 2018.

[9] MICHAELA, T. L. K.; DOROTA, M. et al. Food Sci. Nutr., v 1(4): 267-272, 2013.

[10] CHENG, B.; FURTADO, A. et al. J. Trends Food Sci. Technol., v. 57, p. 20-30, 2016.

[11] COLODETTI, T V.; RODRIGUES, W. N. et al. Aust J. Crop. Sci., v. 8, p. 1648-1657, 2014.

[12] NIKOLOVA-DAMYANOVA, B.; VELIKOVA R.; JHAM G.N. Food Res Int, v. 31, p. 479-486, 1998.

[13] HASENHUETTL, G. L.; WAN, P, J. Journal Am. Oil Chem.' Soc., v.69, n.6, p.525-527, 1992.
[14] PÁDUA, F. R. M.; PEREIRA, R. G. F. A. et al. Revista Brasileira de Armazenamento, Especial Café, Viçosa, v.5, p.15-21, 2002.

[15] PARTELLI, F.L., GONTIJO, I. Café Conilon: Gestão e Manejo com Sustentabilidade, Alegre - ES, CAUFES, 2017.

[16] ALVARES, C.A. et al, Meteorologische Zeitschrift, v. 22, p. 711-728, 2013.

[17] D'AMELIO, N.; DE ANGELISC, E. et al, Talanta, v. 110, p. 118-127, 2013.

[18] VIGLI, G.; Philippidis, A. et al. J. Agric. Food Chem., v. 51, p. 5715-5722, 2003.

[19] CHEN, H. C.; FARESE, R. V. JR., Curr Opin Clin Nutr. Metab. Care., v. 4, p. 359-363, 2002.

[20] SACCHI, R.; PATUMI, M. et al. J. Am Oil Chem, Soc, v. 73(6), p. 747-758, 1996.

[21] ALMEIDA, M. E. W.; AMATO, C., Rev. Inst. Adolfo Lutz 22/23 p. 77-80, 1962.

[22] WENJIANG, D.; LEHE, T., et al. Molecules, v. 20, p. 16687-16708, 2015.

[23] LEDA, B. Q.; ARISLETE, D. A. B., CEPPA Curitiba, v. 22, n. 2, 325-336, 2004.

[24] ROMIJIN, D.; WISEMAN, S. A. et al. Ann. Nutr. Metab. v.42, p. 244-250, 1998.

[25] Food Ingredients Brasil. Disponível em < http://veri sta-fi.com.br/upload_arquivos/201611/2016110700002 001479901769.pdf>. Acesso em: 14 jun. 2018.

[26] YANG, K.; WU, D. et al. J. Agric. Food Chem. v. 61, p. $708-718,2013$.

[27] SANTOS, R. D. et al. I Diretriz sobre o Consumo de Gorduras e saúde Cardiovascular, v. 100, n. 01, p. 8 -11, 2013. Disponível em: http://publicacoes.car diol.br/consenso/2013/Diretriz_Gorduras.pdf, acesso em: 01 de maio de 2018. 